ORIGINAL ARTICLE

\title{
Her-2/neu oncogene amplification in clinically localised prostate cancer
}

\author{
J D Oxley, M H Winkler, D A Gillatt, D S Peat
}

J Clin Pathol 2002;55:1 18-120

See end of article for authors' affiliations

.....................

Correspondence to: Dr J Oxley, Department of Cellular Pathology,

Southmead Hospital,

Westbury on Trym, Bristol

BS10 5NB, UK

jon@jon-oxley.freeserve.co.uk

Accepted for publication

16 January 2001

\begin{abstract}
Aim: To examine the incidence of Her-2/neu oncogene amplification in clinically localised prostate cancer using in situ hybridisation.

Methods: One hundred and seventeen patients, who had undergone radical prostatectomy, were identified and in situ hybridisation was performed on formalin fixed, paraffin wax embedded tissue using the Quantum Appligene probe for Her-2/neu. The enzyme peroxidase was used to detect the probe because this enabled a permanent record to be kept. Tumours in which there were five or more signals in each nucleus in $>20 \%$ of the tumour cells were considered to have a significantly increased copy number. A serial section from these tumours was then hybridised with the chromosome $17 \alpha$ satellite probe. The ratio of the percentage of cells showing an increase in Her-2/neu copy number to the number showing polysomy for chromosome 17 was calculated. A ratio above 2 was considered amplified.

Results: Biochemical recurrence occurred in $50(43 \%)$ patients and $24(21 \%)$ had clinical recurrence. In situ hybridisation for Her-2/neu was accessible in 114 (97\%) patients. A significant increase in copy number was present in two patients $(1.75 \%)$, but chromosome 17 hybridisation showed that the increase was the result of polysomy rather than true amplification. Both these patients had a Gleason score of 7 and stage T3; they also had recurrent clinical disease with distal metastasis within two and 19 months.

Conclusions: Increased Her-2/neu oncogene copy number appears to be rare in clinically localised prostatic adenocarcinoma and is related to chromosome 17 polysomy rather than true amplification. As a result, it would not be a useful biomarker for identifying those patients who will have recurrences after radical prostatectomy.
\end{abstract}

$\mathrm{N}$ umerous prognostic indicators in prostatic adenocarcinomas have been investigated for their ability to select those patients who may have recurrences after radical prostatectomy and who would benefit from adjuvant treatment. One such indicator is the Her-2/neu oncogene, which is located at chromosome 17q21 and encodes one of the epithelial growth factor receptors on the cell membrane. This gene is overexpressed in 25-30\% of breast cancers, and overexpression is associated with a poor prognosis in node positive cases. ${ }^{1}$

Early studies in prostatic adenocarcinoma using immunohistochemistry showed a varying degree of overexpression of the Her-2/neu gene product-from 29\% as reported by Ross and colleagues ${ }^{2}$ to $80 \%$ according to Zhau et al. ${ }^{3}$ The advent of fluorescent in situ hybridisation (FISH) and commercially available DNA probes has enabled the direct visualisation of amplified oncogenes in archival material. In breast cancer, overexpression of the protein has been attributed to gene amplification in $90 \%$ of cases, although a recent study suggests a lower incidence. ${ }^{1}$ No amplification was seen in 53 cases of prostatic adenocarcinoma using differential polymerase chain reaction analysis, ${ }^{4}$ but using FISH, Ross et al found amplification of the gene in $41 \%$ of cases, and this also correlated with tumour recurrence. ${ }^{5}$ A subsequent study using a different commercial probe has shown a lower incidence of amplification of $9.3 \%{ }^{6}$

"The advent of fluorescent in situ hybridisation and commercially available DNA probes has enabled the direct visualisation of amplified oncogenes in archival material" $^{\prime \prime}$
The advent of a humanised monoclonal antibody to the Her-2/neu protein, Herceptin (trastuzumab), and its use as an adjuvant therapeutic agent has stimulated even greater interest in the Her-2/neu oncogene. Recent studies in human prostate xenograft models showed a response to Herceptin in androgen dependent tumours, ${ }^{7}$ but not in androgen independent tumours.

The aim of our study was to examine the amplification of Her-2/neu in the largest series to date, using a modification of the FISH method in which enzymatic techniques rather than fluorescent detection are used.

\section{MATERIALS AND METHODS \\ Patients}

One hundred and seventeen men with clinically localised biopsy confirmed adenocarcinoma of the prostate were included. The median age of the patients was 65 years (range, 50-73). The patients underwent either radical retropubic or perineal prostatectomy at our institution or at the Western General Hospital, Weston super Mare, between October 1987 and December 1998. On digital rectal and clinical examination all were considered to have organ confined disease and all had a negative preoperative isotope bone scan. Ten (9\%) patients received preoperative hormonal neoadjuvant treatment. Histopathological evaluation was performed using the Gleason system.

Abbreviations: FISH, fluorescent in situ hybridisation; PSA, prostate specific antigen, SSC, sodium chloride/sodium citrate solution 


\section{In situ hybridisation}

JO and DP identified formalin fixed, paraffin wax embedded tissue blocks containing representative areas of tumour with the highest Gleason grade. Sections ( $5 \mu \mathrm{m}$ thick) were mounted on to sialinised slides. The sections were dewaxed in xylene, washed twice in $100 \%$ ethanol, and air dried. They were then placed in the pretreatment solution of $30 \%$ sodium bisulphite (Sigma Aldrich, Poole, Dorset, UK) for 45 minutes at $45^{\circ} \mathrm{C}$. Next, the slides were washed in $2 \times$ sodium chloride/sodium citrate (SSC; $0.3 \mathrm{M}$ sodium chloride, $0.03 \mathrm{M}$ sodium citrate at $\mathrm{pH} 7.0$ ). Protein digestion was then carried out by immersing the slides in proteinase K (Sigma Aldrich) at $100 \mathrm{mg} /$ litre for between 30 and 50 minutes at $45^{\circ} \mathrm{C}$. The digestion time was calculated based on the degree of propidium iodide uptake, according to the manufacturer's instructions (propidium iodide antifade; Quantum Appligene Lifescreen, Harefield, Middlesex, UK). After digestion, the slides were dehydrated in $70 \%, 90 \%$, and $100 \%$ ethanol and then air dried. Next, $8 \mu \mathrm{l}$ of Her-2/neu digoxigenin labelled probe/ hybridisation mix was added to the tissue (Quantum Appligene Lifescreen). A $22 \mathrm{~mm}^{2}$ coverslip was then applied and rubber solution used to seal the coverslip. The slides were placed on a hotplate at $70^{\circ} \mathrm{C}$ for five minutes to denature the probe and the tissue DNA. The slides were then incubated in a humidified chamber at $37^{\circ} \mathrm{C}$ overnight. The next day the rubber solution was pealed off and the slides were soaked in $2 \times$ SSC to remove the coverslip. This was followed by a stringency wash in $2 \times \mathrm{SSC}(\mathrm{pH} 7.0)$ at $73^{\circ} \mathrm{C}$ for five minutes. The slides were washed in Optimax wash buffer (Biogenex, Menarini Diagnostics, Reading, UK) and $25 \mu \mathrm{l}$ of 1/20 antidigoxigenin peroxidase (Roche Diagnostic Ltd, Lewes, East Sussex, UK) was applied with a plastic coverslip and incubated for 4 hours at $37^{\circ} \mathrm{C}$ in a humidified chamber. After two further washes in Optimax buffer the enzyme activity was developed using liquid diaminobenzidine (Biogenex) and the slides were counterstained with haematoxylin. Stromal nuclei and benign glands acted as internal controls. In areas of highest signal a hundred nuclei were examined using a $\times 100$ objective and constant adjustment of the microscope focus. A significantly increased copy number was considered to be present if there were five or more signals/nucleus in more than $20 \%$ of the nuclei. ${ }^{5}$

Any tumours that showed increased copy number of Her-2/ neu underwent in situ hybridisation using the same technique on a serial section with a chromosome $17 \alpha$ satellite probe (mixed 1/20 with Hybridsol VI, Quantum Appligene Lifescreen). Scoring was the same as for Her-2/neu, and a ratio of the percentage of cells showing Her-2/neu amplification to the percentage showing chromosome 17 amplification was calculated. If this ratio was greater than 2 then the case was considered to be true amplification.

\section{RESULTS}

Follow up of the 117 patients ranged from 14 to 152 months (median, 53). The median pretreatment serum prostate specific antigen (PSA; Chyron Ltd, Halstead, Essex, UK) was $13 \mathrm{ng} /$ litre (range 1-43). Fifty six (48\%) of these patients were classified as stage pT2, and 61 (52\%) were classified as stage pT3/pT4. Three $(2.5 \%)$ patients had positive lymph nodes at the time of radical prostatectomy (N1). Biochemical recurrence occurred in $50(43 \%)$ patients (defined as a serum PSA of greater than $0.2 \mathrm{ng} /$ litre in at least two consecutive measurements). The median time to recurrence was 12 months (range, 1-66). Twenty four (21\%) had definite clinical recurrence and $12(10 \%)$ have died. Nine $(8 \%)$ had a Gleason score of less than 5, $72(61 \%)$ either 5 or 6 , and $36(31 \%)$ had a Gleason score of 7 or greater.

In situ hybridisation was successful in 114 of the 117 patients. The signal from the probe was highly dependent on the degree of digestion and suboptimal results were repeated.

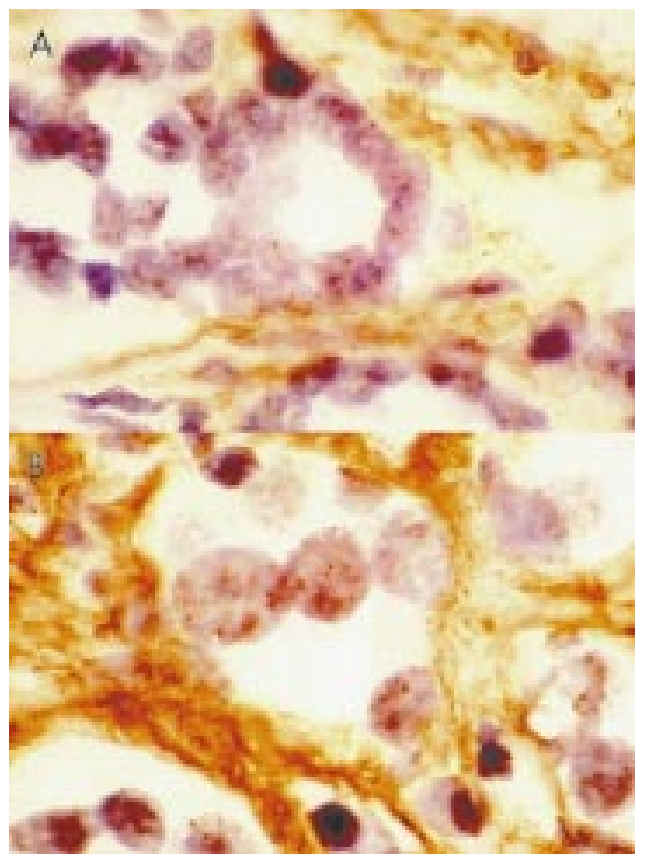

Figure 1 Increased copy number of the Her-2/neu gene in prostate carcinoma detected by means of enzymatic in situ hybridisation. Two prostatic adenocarcinomas: $(A)$ one showing no increase, and $(B)$ one with a significant increase. (Her-2/neu digoxigenin-labelled DNA probe; peroxidase detection; original magnification, $\times 1000$.)

There was a tendency for the signal to be located at the nucleolar membrane (fig lA). A significant increase in the Her-2/neu gene copy number was seen in only two (1.75\%) of the patients and this was at a low level (23\% and 38\%) (fig 1B). The ratios to chromosome 17 were both less than $2(0.8$ and 1.6). These two patients both had a Gleason score of 7; one had a stage pT3A tumour, which clinically recurred with distal metastasis after 19 months. The other had a stage pT3B tumour, which clinically recurred after two months with distal metastasis.

\section{DISCUSSION}

Prostatic adenocarcinoma appears to be increasing in men under the age of 60 in the UK, even when the effects of the increased detection of subclinical cases are accounted for. ${ }^{8}$ Although many biological markers have been studied retrospectively none is used routinely in a prospective manner. The most reliable predictor of recurrence is still the Gleason score and stage, although the expression of p53 and bcl-2 also appear to be useful. ${ }^{9}$ Developments in prostate cancer have lagged behind those made in breast cancer-for example, immunohistochemical assessment of oestrogen receptor status is now undertaken in every breast tumour in the UK. In the USA, the Food and Drug Administration (FDA) has approved the use of two FISH assays of Her-2/neu amplification in certain clinical situations in breast cancer. ${ }^{1}$ One of these FISH assays (INFORM ${ }^{\mathrm{TM}}$ ) uses the Quantum Appligene probe (used in our study) (Ventana Medical Systems, Tuscon, Arizona, USA), whereas the other assay (PathVysion ${ }^{\mathrm{TM}}$ ) uses the Vysis probe (Vysis, Downers Grove, Illinois, USA). The availability of these probes and the therapeutic agent Herceptin has led to increased studies of Her-2/neu in all tumours.

"The most reliable predictor of recurrence is still the Gleason score and stage, although the expression of p53 and bcl-2 also appear to be useful"

Early studies in prostatic carcinomas using immunohistochemistry to detect Her-2/neu gene products showed varied results. This probably resulted from the different antibodies 
Table 1 Previously reported criteria and amplification rates of Her-2/neu in prostate cancer

\begin{tabular}{|c|c|c|c|c|}
\hline First author & Patient numbers & Probe & Criteria for amplification & $\%$ Amplified \\
\hline $\begin{array}{l}\text { Ross }^{5} \\
\text { Mark }^{6} \\
\text { Bubendorf }{ }^{12} \\
\text { Oxley }\end{array}$ & $\begin{array}{l}113 \\
86 \\
262 \text { tumour microarrays } \\
114\end{array}$ & $\begin{array}{l}\text { Quantum Appligene } \\
\text { Vysis } \\
\text { Vysis } \\
\text { Quantum Appligene }\end{array}$ & $\begin{array}{l}\geqslant 5 \text { signals in } \geqslant 20 \% \\
\text { Ratio } \geqslant 1.5 \\
\text { Ratio } \geqslant 3 \\
\geqslant 5 \text { signals in } \geqslant 20 \% \\
\text { Ratio } \geqslant 2\end{array}$ & $\begin{array}{l}41 \% \\
9 \% \\
0 \% \\
1.75 \% \\
0 \%\end{array}$ \\
\hline
\end{tabular}

used, variations in antigen retrieval, and small patient numbers. Similar variations have been found in breast cancers, but with the introduction of a standardised technique (HercepTest ${ }^{\mathrm{TM}}$ ) these problems should be resolved. To date, no study of prostate cancer using this technique has been published.

Using FISH, a high percentage of gene amplification has been found in those cases of breast cancer showing protein overexpression. In prostate cancer, one group has found amplification of the Her-2/neu oncogene in up to $44 \%$ of cases, and this was associated with advanced pathological stage and higher Gleason score. ${ }^{5}{ }^{10}{ }^{11}$ However, more recent work by that group showed a lower amplification rate of $10-25 \%$ (personal communications, JS Ross, 2000). Using the Vysis probe, Mark et al found an amplification rate of 9\%. ${ }^{6}$ The Vysis Her-2/neu probe has a great advantage over the Quantum Appligene probe in that it also contains an internal control of a chromosome $17 \alpha$ satellite probe. As a result, two colour FISH can be used and this allows the ratio of chromosome 17 number to Her-2/neu copy number to be calculated. The major drawback of two colour FISH is its reliance on computer assisted analysis, which may restrict the application of this technology to larger centres.

The largest study of prostate cancer and Her-2/neu amplification used a combination of FISH using the Vysis probe and microarrays. ${ }^{12}$ This technique allowed 262 separate tumours to be assessed by taking small samples $(0.6 \mathrm{~mm}$ in diameter $)$ and mounting them on a single slide, which was then used for FISH. Microarrays have the great advantage of being able to screen large numbers of tumours for gene amplifications, but there can be sampling error, because most tumours are heterogeneous. Bubendorf et al tried to take this into account by using tumours from different stages of the disease-from localised to metastatic. They found Her-2/neu was not amplified at any stage of the disease. ${ }^{12}$

The differences in amplification rates in these studies appear to result from the definition of amplified used by the different investigators (table 1). Ross et al did not control for polysomy, whereas Mark et al used a ratio of 1.5 and Bubendorf et al used a ratio of $3 .^{5612}$ Although no cases of amplification were found by Bubendorf et al there was a single case in the study by Mark et al with a ratio of 3 .

Our study is the largest to date using complete sections of prostatic tumours as opposed to microarrays, and is the first to use enzymatic detection. The major advantages of enzymatic detection are that it provides a permanent record and does not require fluorescent microscopy for scoring. Using the criteria for amplification suggested by Ross et al, ${ }^{5}$ we found two cases of Her-2/neu amplification, but when chromosome 17 polysomy is taken into account none of these should be considered amplified. Interestingly, a recent paper comparing the two probes in breast cancer found that there was concordance in $98 \%,{ }^{1}$ but they used a cut off ratio of 2 for the Vysis probe.

Defining a subset of clinically localised prostatic carcinomas that will have a recurrence post-prostatectomy has led to several biological markers being examined. The Her-2/neu oncogene does not appear to be amplified in early stage disease and

\section{Take home messages}

- Increased Her-2/neu oncogene copy number is rare in clinically localised prostatic adenocarcinoma and is related to chromosome 17 polysomy rather than true amplification

- Her-2/neu copy number is not a useful biomarker for identifying those patients who will have recurrences after radical prostatectomy

as a result will not be useful. Increased copy number does appear to occur in advanced stages of the disease and in hormone unresponsive cases. Intriguingly, early studies in xenografts have shown that the new therapeutic agent Herceptin does not appear to be useful in hormone unresponsive tumours.

\section{ACKNOWLEDGEMENTS}

We thank Dr A Charles for his advice, Dr D Patterson for providing tumour tissue, and S Swann, C Abbott, and K Sibley for their technical work. The Southmead Research Foundation funded this project.

\section{Authors' affiliations}

J D Oxley, D S Peat, Department of Cellular Pathology, Southmead Hospital, Westbury on Trym, Bristol BS10 5NB, UK

M H Winkler, D A Gillatt, Department of Urology, Southmead Hospital

\section{REFERENCES}

1 Wang S, Saboorian MH, Frenkel E, et al. Laboratory assessment of the status of Her- 2 /neu protein and oncogene in breast cancer specimens: comparison of immunohistochemistry assay with fluorescence in situ hybridisation assays. J Clin Pathol 2000:53:374-81.

2 Ross JS, Nazeer T, Church K, et al. Contribution of Her-2/neu oncogene expression to tumour grade and DNA content analysis in the prediction of prostatic carcinoma metastasis. Cancer 1993;72:3020-8.

3 Zhau HE, Wan DS, Zhou J, et al. Expression of c-erB-2/neu proto-oncogene in human prostatic cancer tissues and cell lines. Mol Carcinog 1992;5:320-7.

4 Kuhn EJ, Kurnot RA, Sesterhenn IA, et al. Expression of the c-erbB-2 (Her-2/neu) oncoprotein in human prostatic carcinoma. J Urol 1993; 150:1427-33.

5 Ross JS, Sheehan CE, Hayner-Buchan AM, et al. Prognostic significance of $\mathrm{Her}-2 /$ neu gene amplification status by fluorescence in situ hybridization of prostate carcinoma. Cancer 1997;79:2162-70.

6 Mark HFL, Feldman D, Das S, et al. Fluorescence in situ hybridization study of Her-2/neu oncogene amplification in prostate cancer. Exp Mol Pathol 1999:66:170-8.

7 Agus DB, Scher HI, Higgins B, et al. Response of prostate cancer to anti-Her-2/neu antibody in androgen-dependent and -independent human xenograft models. Cancer Res 1999:59:4761-4.

8 Post PN, Stockton D, Davies TW, et al. Striking increase in incidence of prostate cancer in men aged $<60$ years without improvement in prognosis. Br J Cancer 1999;79:13-17.

9 Brewster SF, Oxley JD, Trivella M, et al. Preoperative p53, bcl-2, CD44 and E-cadherin immunohistochemistry as predictors of biochemical relapse after radical prostatectomy. J Urol 1999;161:1238-43.

10 Ross JS, Sheehan CE, Hayner-Buchan AM, et al. Her-2/neu gene amplification status in prostate cancer by fluorescence in situ hybridization. Hum Pathol 1997:28:827-33.

11 Kallakury BV, Sheehan CE, Ambros RA, et al. Correlation of p34 ${ }^{\text {cdc2 }}$ cyclin-dependent kinase overexpression, CD44s downregulation, and Her-2/neu oncogene amplification with recurrence in prostatic adenocarcinomas. J Clin Oncol 1998;16:1302-9.

12 Bubendorf L, Kononen J, Koivisto $P$, et al. Survey of gene amplifications during prostate cancer progression by high-throughput fluorescence in situ hybridization on tissue microarrays. Cancer Res 1999;59:803-6. 